\title{
TRAINING OF SCHOOL TEACHERS AT FRENCH ASTRONOMY SUMMER UNIVERSITIES
}

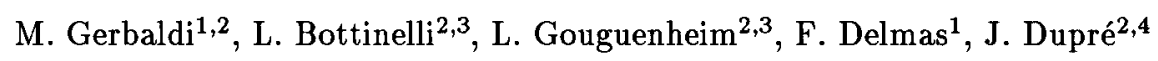 \\ ${ }^{1}$ Institut d'Astrophysique, 98 bis Bd Arago, 75014 Paris, France \\ ${ }^{2}$ Université de Paris XI, Centre d'Orsay, Lab. d'Astronomie Bât 470, 91405 Orsay, \\ France \\ ${ }^{3}$ Observatoire de Paris, Section de Meudon, DERADN, 92195 Meudon, France \\ ${ }^{4}$ Université de Paris XI, Centre d'Orsay, Lab. Infrarouge Bât 350, 91405 Orsay, \\ France
}

\section{Introduction}

In September 1976, at the end of the IAU General Assembly held at Grenoble (France), a one-day meeting concerning the teaching of astronomy was organized by Commission 46. It was decided during this symposium, which brought together 150 French school teachers and 50 astronomers, among other things, to organize a summer school of astronomy the following summer. Since then, such a school has been organized every summer. These astronomy Summer Universities are one of the activities developed by the non-profit organization CLEA (Comité de Liaison Enseignants Astronomes) whose activities are discussed elsewhere in these proceedings. In astronomy, children are always very curious. Because of this interest, in the 1970's some French astronomers applied pressure on the Education Ministry to introduce the subject in schools, and they were successful. However, astronomy was not introduced as a new separate subject, but rather as a part of another subject, mainly mathematics or physics.

Since few secondary school teachers receive instruction in astronomy during their university education, they need to be trained in astronomy. It is well known that one achieves better understanding of a subject by concentrated involvement. The solution adopted for training was therefore to be together, school teachers and astronomers, for 10 days in an isolated place. Table 1 lists the Summer Universities held to date.

In what follows, the methods used during these Summer Universities and the results will be discussed.

\section{Objectives of the Summer Universities}

The objectives of these Summer Universities are those of the CLEA. The aims can be expressed on one hand concerning content and on the other hand concerning pedagogical methods; both sides are equally important. 
Table 1. Summer Universities Held in France.

Number of participants (not including the pedagogical team members)

Organizers

\begin{tabular}{lllllr}
\hline & $\begin{array}{l}\text { Bottinelli, L. } \\
\text { Delmas, F. }\end{array}$ & $\begin{array}{l}\text { Acker, A. } \\
\text { Parisot, J.P. }\end{array}$ & Celnikier, L. & $\begin{array}{l}\text { Duval, M.F. } \\
\text { Donas, J. }\end{array}$ \\
Year & $\begin{array}{l}\text { Dupre, J. } \\
\text { Gerbaldi, M. } \\
\text { Gouguenheim, L. }\end{array}$ & & & Total \\
& & & & \\
\hline 1977 & 69 & & & & 69 \\
1978 & 63 & & 55 & & 118 \\
1979 & 67 & 50 & & 117 \\
1980 & 55 & & & 55 \\
1981 & 61 & & & 135 \\
1982 & 80 & & & 70 \\
1983 & 70 & & & 91 \\
1984 & 91 & & & 132 \\
1985 & 82 & & & 168 \\
1986 & 98 & & & 94 \\
1987 & 79 & & & 136 \\
1988 & 61 & 50 & & 25 & \\
\hline
\end{tabular}

The content varies from one year to another and covers a wide range. It can be related to a specific program, for example:

- in elementary classes (pupils from the age of 7 to 9): notions of time and space

- in secondary school programs:

pupils between the age of 13 to 14: physics program: optics

pupils between the age of 16 to 17: physics program: stellar evolution pupils between the age of 17 to 18: mathematics program: history of ideas.

It can also be related to some specific astrophysical concepts, for example:

- the various coordinate systems

- the use of the Universe as a unique laboratory considered as an extension of any terrestrial laboratory, to be able to have a better understanding of the approximations of the physics laws deduced from experiences on Earth.

Concerning methods, the goals are for any participant:

- to be able to choose from all the activities proposed, the one best suited to him

- to be able to develop his critical awareness, elaborating on what can be read in books 
- to be willing to ask questions

- to be willing to explain his pedagogical experiences in a classroom

- to learn to use pedagogical tools such as: overhead projector, models, planetariums, microcomputers, other audiovisual equipment

- to be able to communicate with other teachers who attend the same Summer University but who are teachers of different subjects. This point is important: the school teachers who attend a Summer University have various backgrounds. Table 2 divides the participants of the previous Summer Universities by their backgrounds. The participation in a Summer University is not restricted by the background of the school teacher: the only rule for registration is: "first come, first served." The mixing of school teachers with different backgrounds enriches everybody.

Table 2. Typical Backgrounds of the Participants. (1988 Summer University)

Teaching Level

Background

\begin{tabular}{lrrlll}
\hline Primary School Teachers & 8 & $\%$ & Mathematics & 10 & $\%$ \\
Secondary School Teachers & 50 & $\%$ & Physics & 71 & $\%$ \\
(1st level) & & & & & \\
Secondary School Teachers & 42 & $\%$ & Physics-Chemistry & 8 & $\%$ \\
& & & Earth Sciences & 7 & $\%$ \\
& & & Non-Science & 4 & $\%$ \\
\hline
\end{tabular}

We also want to push very hard the following ideas:

- we are very much in favor of using the history of science to acquire knowledge: astronomy is very suitable for that purpose

- we wish to show that recent developments in astrophysics can be introduced in classrooms.

\section{Pedagogical Strategy}

During a Summer University there are 3 categories of activities:

- lectures (9:00 - 12:00 noon)

- small workshops and practical classes (2:30 - 4:30 and 5:00 - 7:00 p.m.)

- tutorials (9:00 - 10:00 p.m.)

- night observations (10:00 p.m. - )

a) Lectures

The lectures are always in the morning. They last 3 hours and all the participants attend them. During the last 5 years, the lecturers have been L. Bottinelli, 
J. Dupré, F. Durret, M. Gerbaldi, L. Gouguenheim, M. Gros, G. Paturel, J. Ripert, B. Sandré, V. Tryoën, and G. Walusinski, as well as A. Acker and M.F. Duval. The aim of these lectures is to give all the participants some basic facts. For example:

- the analysis of light in astrophysics

- a reflection of epistemological type (that is, the study of the nature, sources, and limits of knowledge), for example: the representation of the solar system during the 17 th century

- modern astrophysics (cosmology).

Of course not all these subjects are developed during the same year.

b) Small workshops and practical classes

The activities are organized into small workshops or into practical classes of 10 persons according to the subject: theoretical or more practical. Everyone can choose from all the activities proposed. Several workshops and classes run in parallel. The small workshops and practical classes are always during the afternoon and are directed by a tutor.

The overall aim of these activities is to illustrate an astrophysical concept that may have been presented during the lectures. Therefore, during the afternoon, activities considered include:

i) the analysis of a collection of data or of a series of photos (generally obtained by professional astronomers)

The exercises cover a broad range of subjects, for example:

- analysis of light:

- motion (Doppler effect)

- magnitude determination

- temperature determination

- coordinates and time

- history of astronomy (Kepler's laws)

During a Summer University about 30 different such small workshops are available.

ii) the making of models

During a practical class, the participants make themselves a model or a small instrument that can be used during the following nights to make an observation. 
For the construction of these small instruments out of cardboard or wood, we intend to allow every participant to make his own instrument and to take it home. We therefore prepared ready-made pieces to avoid wasting too much time. Further, everybody can make his own instrument even if not skilled at using materials and tools.

Among the models and instruments so far made were:

- an astrolabe

- a model of the solar system (to scale)

- an heliograph

- a simplified equatorial mount

- a refractor (diameter $5 \mathrm{~cm}$ )

25 such projects are carried out during a Summer University (see Bottinelli et $a l .$, in these same proceedings).

iii) carrying out an observational sequence; for anyone studying astronomy it is necessary to be practical and to observe the heavens with the naked eye, with binoculars, or with a small telescope

These activities are not designed for future use in the classroom. Participants must adapt them to the level of their pupils. We do not want to give packages of "ready-made" lessons.

During the Summer University, there are some informal sessions in which the participants discuss how to adapt the activities they have learned to their pupils. Moreover, every evening, tutorial sessions are designed to clear up any aspects that were not understood during the lectures. These tutorial sessions are organized at the demand of the participants themselves, to counterbalance the great variety among the backgrounds of the participants. The instructor for any of these activities can be either an astronomer or a school teacher who has himself acquired sufficient knowledge in some astronomical field.

During the last 5 years, the main instructors were: R. Arhel, D. Bardin, C. Canard, F. Dahringer, A. Dargencourt, Ch. Dumoulin, J.L. Fouquet, M. Jonas, R. Gouguenheim, C. Piguet, J. Ripert, A. Rivière, M. Rivière, B. Sandré, D. Toussaint, V. Tryoën, and C. Vignon.

The methods used in a small workshop are direct and concise because we want to have a high efficiency level in a short time. But each instructor is free to choose any method he wishes to use. Because of the fact that there are many instructors in a Summer University, the methods used can vary greatly. In any case, each participant is absolutely free to choose any activity he likes.

\section{Organization of these Summer Universities}

The organization and the putting into practice of a Summer University of 80 participants is done by a pedagogical team that consists of professional astronomers 
and school teachers. Such a team consists typically of 6 astronomers and 10 school teachers. The members of this team share the organization of the Summer University.

\section{a) Pedagogical organization}

Many activities are available for the participants. Before the beginning of the Summer University, each participant receives a short description of all the activities offered.

On the first day of the school, one of the organizers explains the program in detail so every participant can make his own daily plan.

Of the activities put forward, some had been developed during the preceding school year by school teacher members of the pedagogical team. In this way, the content of the Summer University is enriched by feedback.

This pedagogical organization requires a certain environment, such as:

- a library

- a small workshop

- a small photographic lab as much for the development of photographs as for their printing on paper

- a small color lab to develop slides.

b) Practical organization

The practical organization is as much concerned with housing the participants as with putting together all the equipment needed.

First, we must find a location where the Summer University can take place. Since it must be favorable for night observation, we must be far from a city. Further, housing for 100 people and both board and catering must be available. Moreover, a conference room for 100 participants and several ( 6 to 7 ) small rooms must be available for practical classes, since the latter run in parallel sessions during the afternoons. We need also a place to organize the workshop as well as suitable rooms for the photographic labs. A place that fulfills all those requirements is generally a summer residence.

To take care of the registration of the participants as well as of their housing, a team member is fully in charge, some weeks before and during the Summer University, of the lodging and its financial counterpart. Before the Summer University, some amount of work is necessary to put together all the equipment needed. We have to buy wood, cardboard, some tools, nails, screws, and so on...used in the practical classes. We must also reproduce all the documents needed during the small workshop and pre-cut pieces of wood or of cardboard for the making of the models.

Concerning the funds necessary for such a school, the CLEA succeeded in obtaining financial support from the CNRS (Centre National de la Recherche Scientifique), the CNFA (Comité National Français d'Astronomie) and for the past 4 
years from the Educational Ministry, but in the last year we had to be selected from many proposals covering a wide range of subjects.

The participants need only pay for their board and meals. All the funds collected are used for the equipment needed. None of the lecturers receives any fee. In order that the summer residence can function as a Summer University, some team members must be there two days in advance to put everything in order.

The total volume of all the equipment needed is 12 cubic meters for a Summer University of 80 participants. To transport the equipment from our University (Paris XI), where it is used also with the students, we used to rent a small truck and drive it ourselves from Paris to the location (roughly $900 \mathrm{~km}$ ). This summer we contracted a moving company to transport all the equipment.

\section{The Feedback}

How to evaluate what the participants had acquired during the school?

We evaluate it throughout the courses by informal reports or during the tutorial sessions in the evening. But the major evaluation is done the last day during a poster session, during which small groups of participants (one for each practical class) present how a model is made, how it functions, and what its use is.

The last day of the Summer University, we distribute to all the participants a questionnaire concerning the content, the methods, the pace, and the way the Summer University was carried out. This questionnaire is of great help for organizing the next Summer University.

Moreover after the end of the Summer University, some months later we used to publish the proceedings, including the text of all the lectures as well as that of the small workshops. We did so 11 times, but as it became more and more expensive and time consuming, and because during the 11 years all the major subjects were described in one way or another in one of the previous proceedings, we decided this year not to publish that way. Instead, during the Summer University, we distributed to every participant the full text of all the lectures as well as the reports written down for the poster session, which were photocopied during the Summer University.

We try also to keep in touch with participants during the year that follows, through the non-profit organization CLEA.

\section{Conclusion}

Figure 1 shows that these Summer Universities contribute to the training of the school teachers from every region in France. The number of teachers who have been trained since 1977 varies greatly from one region to another, but is in fact, proportional to the number of pupils in each region.

We conclude that - despite the fact that, in France, astronomers are concentrated in a limited number of observatories and institutes that are not linked with the universities - the method of school teacher-training by Summer Universities is powerful in the sense that it reaches school teachers far from astronomical centers.

On a different level, another success of these Summer Universities is that some 
of the teachers, after attending several times, can then become tutors. Not only do they propose new experiments and test them with their colleagues, but they also organize local training in astronomy during the school year, in their districts.

\section{Acknowledgment}

We would like to express our deepest thanks to F. Warin for all the photographic work she does for the Summer Universities.

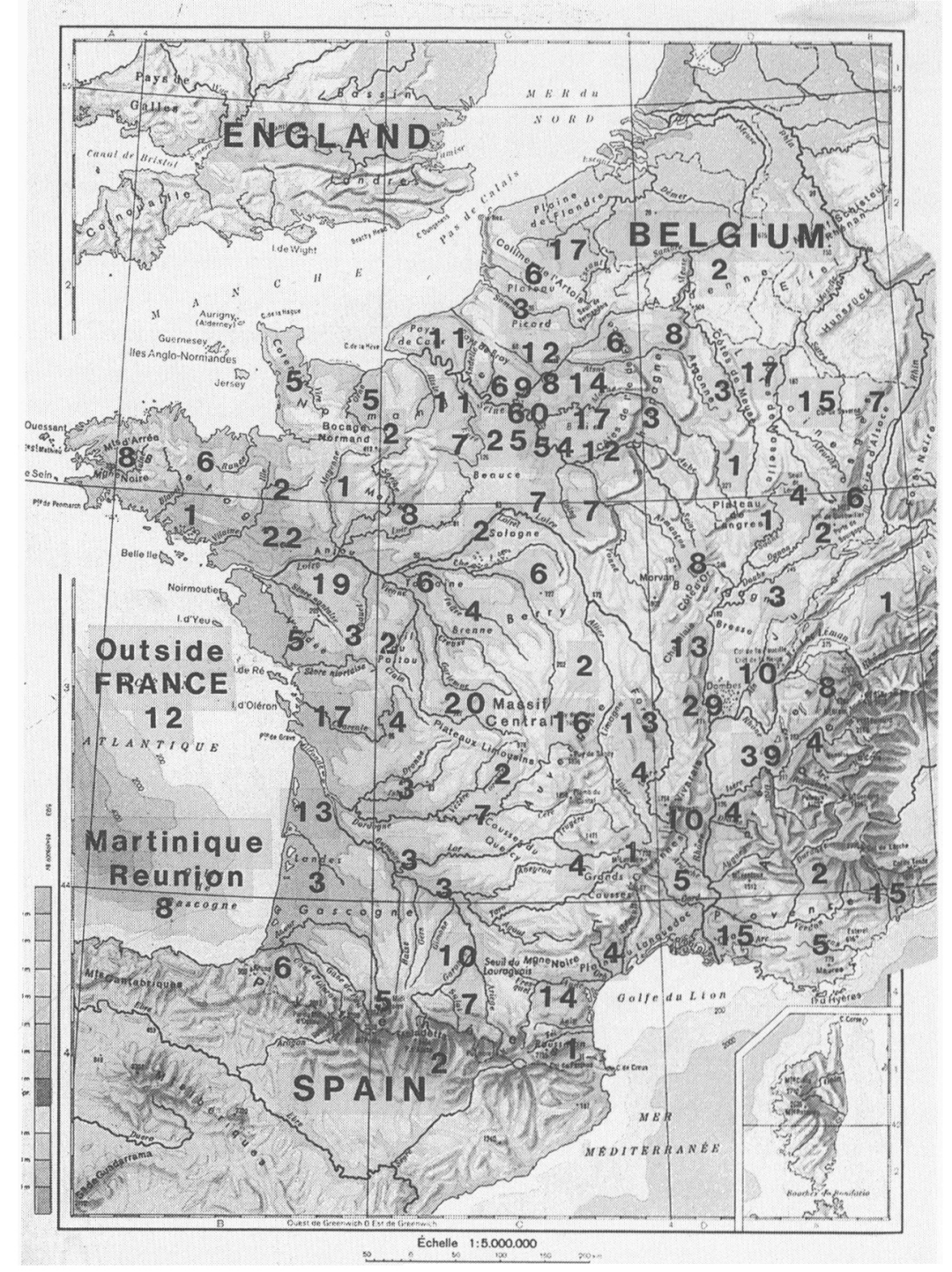

Figure 1: Geographical distribution of the school teachers who attended the Summer Universities, organized by L. Bottinelli, et al., since 1977. "Outside France" means teachers who are teaching in French Lycées located in foreign countries. 
Gerbaldi et al.: Training of Teachers at Astronomy Summer Universities

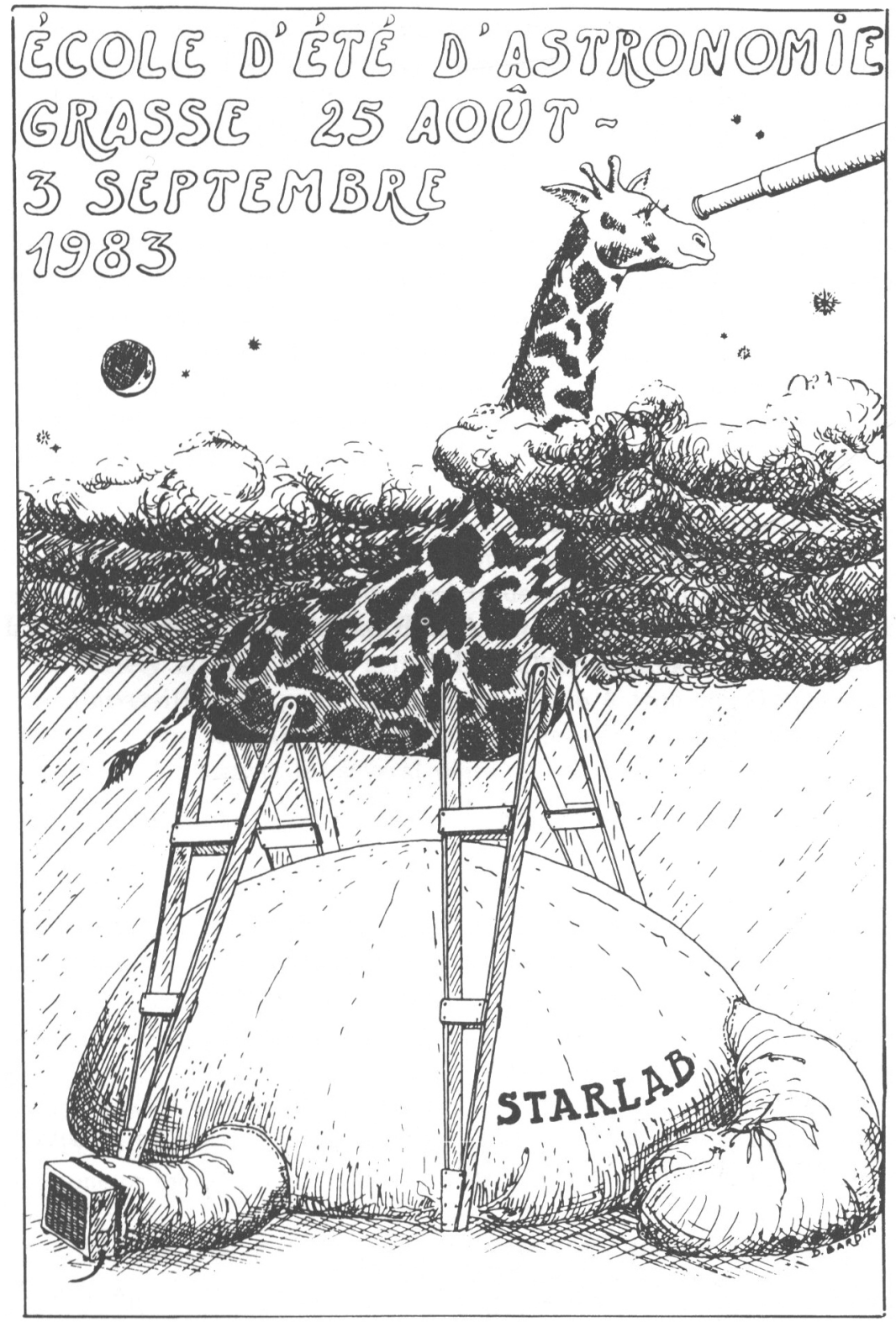

Figure 2: Cover of the Proceedings of a Summer University (drawing by D. Bardin)

\section{Discussion}

H. Shipman: First, let me say how impressed I am with the number of teachers involved and the variety and depth of activities. My question is how do the elementary teachers react to your program; are they overwhelmed by the program, or are they as pleased as the high school teachers? 
M. Gerbaldi: We are very careful to ask participants about their backgrounds, and structure activities accordingly. The participants were very satisfied.

C. Iwaniszewska: I would like to comment about the publication of the big volume after the Summer University; it is a lot of extra work for the organizers, but is so very useful for participants.

M. Gerbaldi: This year, in 1988, we reproduced the text of all the lectures before the beginning of the Summer University in order to give them immediately to the participants. For the results of the small workshops and the practical classes, small groups of participants wrote down, in a few pages, the results they obtained and how the scale models or the small instruments were made. We rented a photocopy machine to reproduce all these reports and they were distributed to all the participants. Thus this year, every participant went home with the proceedings.

\section{THE UNIVERSE IN THE CLASSROOM: A NEWSLETTER ON ASTRONOMY FOR TEACHERS}

\section{Andrew Fraknoi}

Astronomical Society of the Pacific, 390 Ashton Ave, San Francisco, California 94112 , U.S.A.

Since 1984, the Astronomical Society of the Pacific (ASP) has sponsored a quarterly newsletter on teaching astronomy in grades 3-12. Cosponsored by the American Astronomical Society, the Canadian Astronomical Society, and the International Planetarium Society, the project now reaches over 20,000 teachers and schools in the US and Canada.

We would like colleagues overseas to examine the newsletter, and, if they find it useful, to consider translating and distributing it. We will be glad to make it available without charge to anyone who is interested.

\section{The History of the Newsletter}

Since 1978, the summer meetings of the ASP - held in a different city each year - have featured one to three days set aside for workshops on astronomy for teachers. In recent years, between 150 and 200 teachers have come each summer - at their own expense - to take these credit workshops and learn more about astronomical topics, activities, and resources.

Participants in these workshops asked the ASP year after year if we could set up a way for the "graduates" to keep in touch with us and continue to get updates, especially about new discoveries and new teaching resources. In late 1984, with a 